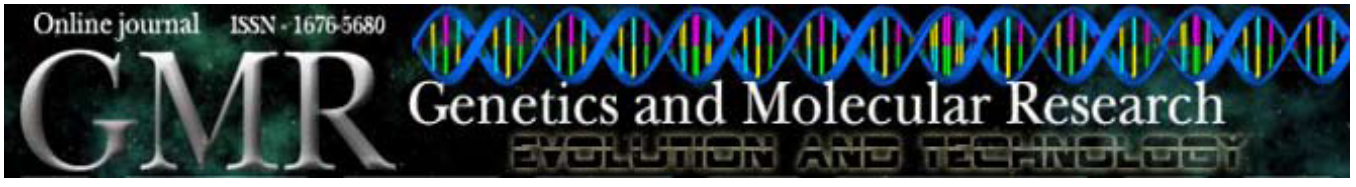

\title{
The azoospermia factor locus-c region was found to be related to Klinefelter syndrome in Turkish patients
}

\author{
C. Ceylan ${ }^{1}$, G.G. Ceylan ${ }^{2}$ and T.A. Serel ${ }^{3}$ \\ ${ }^{1}$ Departments of Urology, Elazığ Research and Training Hospital, \\ Elazı ̆̆g, Turkey \\ ${ }^{2}$ Department of Genetics, Firat University, School of Medicine, \\ Elazı ̆̆, Turkey \\ ${ }^{3}$ Süleyman Demirel University, School of Medicine, Isparta, Turkey \\ Corresponding author: C. Ceylan \\ E-mail: ceylacavit@yahoo.com
}

Genet. Mol. Res. 9 (2): 1229-1233 (2010)

Received March 4, 2010

Accepted April 3, 2010

Published June 29, 2010

DOI 10.4238/vol9-2gmr826

\begin{abstract}
We looked for a possible association between Klinefelter syndrome (KFS) and microdeletions in the Y chromosome in Turkish KFS patients. We examined the frequency of KFS in male patients with proven non-obstructive azoospermia and the types of $\mathrm{Y}$ chromosome microdeletions in these KFS patients. Fifty azoospermic patients and 50 fertile men were included in this study. KFS was found in 14 azoospermic patients. $\mathrm{Y}$ chromosome microdeletions were found in eight KFS patients. Azoospermia factor locus c (AZFc) was the most commonly deleted interval in KFS patients. All KFS patients had elevated plasma follicle-stimulating hormone and luteinizing hormone concentrations, but they had normal plasma testosterone concentrations. Testis biopsy of five samples with Y microdeletions revealed Sertoli cell-only syndrome. No Y microdeletions were found in the fertile group. We concluded that there could be an association between the AZFc region and KFS. Screening for this should be part of diagnostic work-up, particularly in those considering assisted reproduction.
\end{abstract}

Key words: Azospermia; Klinefelter syndrome; AZF region 


\section{INTRODUCTION}

Infertility is usually described as the inability of a couple to conceive after one year of unprotected intercourse (Griffin and Finch, 2005). Infertility is a major health problem today affecting about $10-20 \%$ of couples (Mittal et al., 2004). The male factor is assumed to be responsible in about $50 \%$ of the infertile couples.

Not only defects in hormone production, testicular structure, ejaculation, and/or the spermatozoa themselves can adversely affect the chances of conception, but genetic defects can also affect fertility (Griffin and Finch, 2005). The incidence of chromosome abnormalities is about ten times higher in infertile men than in the general population (Egozcue et al., 2003). Klinefelter syndrome (KFS), 47,XXY and its variants are the most common chromosomal aberrations among men, with estimated frequency of 1:500 among newborns. Men with KFS present sequels of hormonal and spermatogenic testicular failure like infertility, low testosterone, erectile dysfunction, and low bone mineral density (Paduch et al., 2009). Microdeletions of the Y chromosome removing the azoospermia factor (AZF) region or parts thereof are the most frequent genetic cause of spermatogenic failure after KFS (Hucklenbroich et al., 2005). Early diagnosis and treatment can improve the quality of life and the overall health of men with KFS. Because nothing is known about the association of KFS with microdeletions of Y chromosome in Turkish KFS patients, this prospective study was performed. We also aimed to show to clinicians the importance of genetic screening in KFS patients.

\section{MATERIAL AND METHODS}

Infertile men with non-obstructive azoospermia $(\mathrm{N}=50)$ were prospectively recruited for chromosomal analysis from 2006 to 2008 at the Firat University Medical Center and Süleyman Demirel University School of Medicine. The patients who applied because of severe male-factor infertility and past history of infertility for more than two years were selected. The mean age of the patients was 30.5 years (range 20-46 years). All underwent an andrological work-up, which included medical history, physical examination, hormonal estimation (excluding those with obstructive azoospermia), and semen analysis according to World Health Organization recommendations and standards (Tuarnaye, 2002). Fifty normozoospermic male donors with normal semen parameters (sperm count $>20 \times 106 / \mathrm{mL}$, progressive motility $>50 \%$ and normal morphology $>30 \%$ ) and proven fertility were included as controls. None of them had any history of childhood disease, environmental exposure, radiation exposure, or prescription drug usage that could account for their infertility.

Informed consent was taken from the patients and donors prior to collection of heparinized blood samples. Chromosome investigations were performed on cultures of peripheral blood lymphocytes using standard techniques (Barch et al., 1997). From each patient, 50 well-spread metaphases were analyzed by G-banding. All chromosomal abnormalities have been reported in accordance with the current international standard nomenclature (Shaffer and Tommerup, 2005). To screen for microdeletion in the AZF region of the Y chromosome by polymerase chain reaction (PCR), genomic DNA was prepared from the peripheral blood samples. Each man was analyzed for the presence of sequence tagget site (STS) in the AZFa, $\mathrm{AZFb}$ and AZFc regions. The STS probes used were sY84 and sY86 (AZFa), sY127, sY133 and sY134 (AZFb), sY254 and sY255 (AZFc), and SRY and ZFX/ZFY (controls). In addition, 
a water sample that contains all reaction components except for water instead of DNA was used for reagent contamination. PCR conditions used for STS markers were as follows: initial denaturation at $94^{\circ} \mathrm{C}$ for $5 \mathrm{~min}$ and subsequent denaturations at $94^{\circ} \mathrm{C}$ for $30 \mathrm{~s}$ were the same for all samples. Annealing was $56^{\circ} \mathrm{C}$ for $40 \mathrm{~s}$ and extension was $65^{\circ} \mathrm{C}$ for $4 \mathrm{~min}$. Subsequent series were 35 cycles.

Final extension was carried out at $72^{\circ} \mathrm{C}$ for $5 \mathrm{~min}$. The PCR products were separated on a $2 \%$ agarose gel stained with ethidium bromide and visualized using ultraviolet illumination. A PCR of the expected size was scored positive for the given STS, and scored negative if no product was detectable after 3 successive rounds of PCR.

\section{RESULTS}

Among 50 azoospermic infertile men studied, 18 performed some kind of constitutional chromosomal abnormality corresponding to a frequency of $36 \%$. KFS was found in 14 azoospermic patients (28\%). Table 1 summarizes the karyotypes of the azoospermic patients and the control group. Y chromosome microdeletion was determined in 2 azoospermic patients and 8 KFS patients. Five of the 14 KFS patients showed deletions in AZFc regions (Figure 1). None of the KFS patients showed deletions in AZFa and AZFb regions. None of the fertile men had any Y chromosome microdeletions.

Table 1. Karyotypes of azoospermic patients and the control group.

\begin{tabular}{lcc}
\hline Karyotypes & Azoospermics & Control \\
\hline $46, X Y($ normal $)$ & $32(64 \%)$ & $50(100 \%)$ \\
$47, X X Y$ & $14(28 \%)$ & $2(4 \%)$ \\
$46, X Y, Y q h(+)$ & $2(4 \%)$ & - \\
$47, X Y Y$ & - & - \\
$46, X Y, \operatorname{inv}(9)$ & - & \\
inv(9) & & - \\
$46, X Y$, inv $(9)$ &
\end{tabular}

Data are reported as frequency with percentages in parentheses.

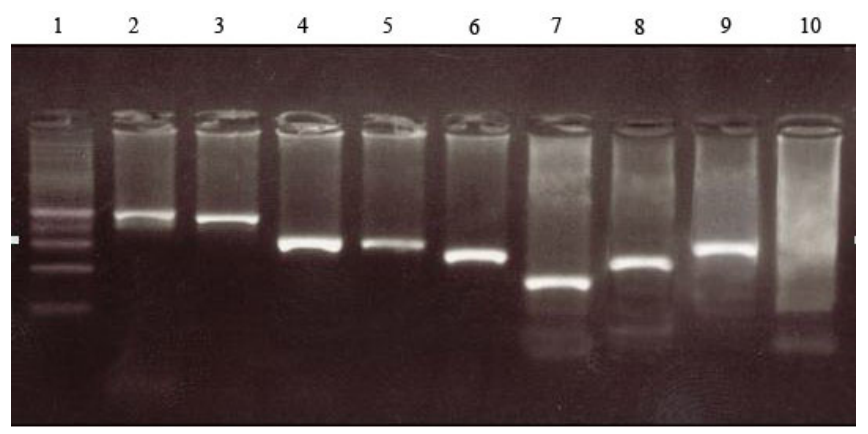

Figure 1. Image of a patient with Klinefelter syndrome with a deletion of the AZFc region (sY255: there is no band). Lane $1=\mathrm{DNA}$ ladder for $100 \mathrm{bp}$; lane $2=\mathrm{ZFY} / \mathrm{ZFX}$; lane $3=\mathrm{SRY}$; lane $4=\mathrm{sY} 84$; lane $5=\mathrm{sY} 86$; lane $6=$ $\mathrm{sY} 127$; lane $7=\mathrm{sY} 133$; lane $8=\mathrm{sY} 134$; lane $9=\mathrm{sY} 254$; lane $10=\mathrm{sY} 255$. 
Hormone profiles were high in the KFS patients. A routine testicular biopsy was carried out in 14 patients with KFS. Five cases with AZFc deletions had Sertoli cell-only syndrome (SCO), 5 with 47,XXY had bilateral hypotrophy, and 4 cases with 47,XXY/46,XY had bilateral hypotrophy.

\section{DISCUSSION}

In this study, we performed microdeletions on Y chromosome in KFS patients in a Turkish population. Chromosomal deletion incidence was found to be $35 \%$ in the KFS patients. As mentioned in the literature, there are some conflicting reports on the occurrence of Y chromosome microdeletions in KFS patients (Tateno et al., 1999; Ambasudhan et al., 2003; Choe et al., 2007). Tateno et al. (1999) failed to find microdeletions in KFS patients. The current study illustrates deletions in the AZFc region in contrast to the deletions AZFa and AZFb in KFS patients by Mitra et al. (2006) and the AZFa, AZFb and AZFc combined deletions by Mitra et al. (2006) and Hadjkacem-Loukil et al. (2009). Deletions in the AZFc regions were found in $5 \mathrm{KFS}$ patients (35\%). However, deletions in the AZFa and AZFb regions were not determined in our study.

The higher percentage of only AZFc deletions observed in this population could be explained by the Turkish origin.

This study analyzed, for the first time, the occurrence of deletions of the AZFc region in a small sample of Turkish KFS patients. AZFc deletions are generated by intrachromosomal homologous recombination between repeated sequence blocks called 'amplicons' organized in palindromic structures with nearly identical sequences in each palindrome arm. Within the $\mathrm{AZFc}$ region there are several candidate fertility genes, including three copies of BPY2 (basic protein on Y chromosome 2), two copies of CDY1 (CDY1a and CDY1b; chromodomain protein, Y chromosome 1), and four copies of the DAZ (deleted in azoospermia) gene family (McElreavey et al., 2000; Kuroda-Kawaguchi et al., 2001). The patients with KFS are known to have progressive deterioration of their testicular architecture. The high concentrations of FSH are in agreement with very low concentrations of inhibin-B and high concentrations of FSH reported in KFS patients (Tomasi et al., 2003). The testis biopsy report from 10 patients showed an SCO type of morphology in 2 cases and bilateral hypotrophy in others. The findings of Kamp et al. (2001) suggest an association between AZF deletions and KFS in men with SCO syndrome. Deletions of the AZFc region are usually associated with hypospermatogenesis and SCO syndrome type II (Krausz et al., 2000). Deletions in the AZF region can be interpreted as to more severe phenotypes such as SCO syndrome, which are in agreement with the present results. However, we believe that the larger studies are needed to show the association between AZF deletions and SCO syndrome in KFS patients.

In conclusion, due to observed $\mathrm{Y}$ chromosome microdeletions in KFS patients, the analysis may be imperative in routine clinical follow-up of such cases, followed by genetic counseling with respect to the risk of transmitting Y chromosome microdeletions to the male progeny, if the patients opt for assisted reproductive techniques. Meanwhile growing interest in KFS among translational scientists and clinicians will result in better understanding of the pathophysiology of testicular failure. The screening programs for KFS may increase the number of patients with KFS seen by practicing urologists in the near future. Diagnosis and management of patients with KFS is within the scope and training of urologists. 


\section{REFERENCES}

Ambasudhan R, Singh K, Agarwal JK, Singh SK, et al. (2003). Idiopathic cases of male infertility from a region in India show low incidence of Y-chromosome microdeletion. J. Biosci. 28: 605-612.

Barch MJ, Knutsen T and Spurbeck JL (1997). The AGT Cytogenetics Laboratory Manual. 3rd edn. Lippincott-Raven, Philadelphia.

Choe JH, Kim JW, Lee JS and Seo JT (2007). Routine screening for classical azoospermia factor deletions of the Y chromosome in azoospermic patients with Klinefelter syndrome. Asian J. Androl. 9: 815-820.

Egozcue J, Blanco J, Anton E, Egozcue S, et al. (2003). Genetic analysis of sperm and implications of severe male infertility - a review. Placenta 24 (Suppl B): S62-S65.

Griffin DK and Finch KA (2005). The genetic and cytogenetic basis of male infertility. Hum. Fertil. 8: 19-26.

Hadjkacem-Loukil L, Ghorbel M, Bahloul A, Ayadi H, et al. (2009). Genetic association between AZF region polymorphism and Klinefelter syndrome. Reprod. Biomed. Online 19: 547-551.

Hucklenbroich K, Gromoll J, Heinrich M, Hohoff C, et al. (2005). Partial deletions in the AZFc region of the Y chromosome occur in men with impaired as well as normal spermatogenesis. Hum. Reprod. 20: 191-197.

Kamp C, Huellen K, Fernandes S, Sousa M, et al. (2001). High deletion frequency of the complete AZFa sequence in men with Sertoli-cell-only syndrome. Mol. Hum. Reprod. 7: 987-994.

Krausz C, Quintana-Murci L and McElreavey K (2000). Prognostic value of Y deletion analysis: what is the clinical prognostic value of $\mathrm{Y}$ chromosome microdeletion analysis? Hum. Reprod. 15: 1431-1434.

Kuroda-Kawaguchi T, Skaletsky H, Brown LG, Minx PJ, et al. (2001). The AZFc region of the Y chromosome features massive palindromes and uniform recurrent deletions in infertile men. Nat. Genet. 29: 279-286.

McElreavey K, Krausz C and Bishop CE (2000). The human Y chromosome and male infertility. Results Probl. Cell Differ. 28: 211-232.

Mitra A, Dada R, Kumar R, Gupta NP, et al. (2006). Y chromosome microdeletions in azoospermic patients with Klinefelter's syndrome. Asian J. Androl. 8: 81-88.

Mittal RD, Singh G, Srivastava A, Pradhan M, et al. (2004). Y chromosome micro-deletions in idiopathic infertility from Northern India. Ann. Genet. 47: 331-337.

Paduch DA, Bolyakov A, Cohen P and Travis A (2009). Reproduction in men with Klinefelter syndrome: the past, the present, and the future. Semin. Reprod. Med. 27: 137-148.

Shaffer LG and Tommerup N (2005). An International System for Human Cytogenetic Nomenclature. 1st edn. S. Karger, Basel.

Tateno T, Sasagawa I, Ichiyanagi O, Ashida J, et al. (1999). Microdeletion of the DAZ (deleted in azoospermia) gene or the YRRM (Y chromosome ribonucleic acid recognition motif) gene does not occur in patients with Klinefelter's syndrome with and without spermatogenesis. Fertil. Steril. 71: 746-749.

Tomasi PA, Oates R, Brown L, Delitala G, et al. (2003). The pituitary-testicular axis in Klinefelter's syndrome and in oligo-azoospermic patients with and without deletions of the Y chromosome long arm. Clin. Endocrinol. 59: 214-222.

Tuarnaye H (2002). Gamete Source and Manipulation. In: Current Practices and Controversies in Assisted Reproduction: Report of a WHO Meeting (Vayana E, Rowe PS and Griffin PD, eds.). WHO (World Health Organization), Geneva, 83-101. 